\title{
Construction Optimisation of the Lift Carrying Frame Suspension by Using a Numerical Fatigue Analysis
}

\author{
Paweł Lonkwic ${ }^{1}$ \\ 1 The State School of Higher Education in Chełm, ul. Pocztowa 54, 22-100 Chełm, Poland \\ e-mail: plonkwic@gmail.com
}

\begin{abstract}
Numerical analysis of deflection for the existing solution of the friction lift carrying ropes suspension was presented in this article. A similar analysis for the optimized bracket of the carrying ropes suspension was demonstrated from the geometrical point of view. Finite Element Method was used for calculations. It allows mapping the actual operating conditions by using commercial SolidWorks software. Geometrical modifications of the bracket were proposed to save time of manufacturing the detail parts. On that basis, the calculations of percentage indicator of the construction damage and its durability were performed in both cases .
\end{abstract}

Keywords: FEM, fatigue, a friction lift, simulation, durability, Solid Works.

\section{INTRODUCTION}

Numerical methodsare becoming more and more popular in optimising the construction. They are used both to save time and money for expensive construction prototyping. The analyses of construction performed with FEM are found in the majority of mechanical sectors of industry. A static numerical analysis was performed to assess the effort and deflection of the beams assembly in a heavily-loaded vehicle loaded by empty weight and acceptable maximum loading capacity of the vehicle are presented in [8]. The results of experimental tests and numerical simulations conducted for braking process of a roller installed in a new CHP 2000 type progressive safety gear were presented in the publication [4]. ABAQUS program was employed as a numerical tool and a commercial packet was used for calculations using Finite Element Method. The results of Finite Element Method simulation for a C-shaped frame installed in a device used to install the joints of sheet metal constructions were presented by the authors of the publication [5]. In the analysis of the frame material effort, a couple of versions of its geometry including the mass reduction were taken into account. ABAQUS program was used for this purpose. The program allows performing quantitative and qualitative assessment of the frame material effort. In the publication [2] the results of numerical analysis for the semitrailer frame construction of a variable length and an increased load capacity intended to transport over standard loads were presented by the authors. The scientific research aimed at developing reliable FEM numerical models to identify the construction effort and deformation degree under the conditions of operating loadings. Finite Element Method was used to model the means to increase stiffness of the panels made of titanium by using cross-shaped stiffeners by the authors in the publication [9]. Numerical calculations were performed with PamStamp 2G based on Finite Element Method. Fundamental mechanical and technological properties of analysed sheets which are indispensable for numerical modeling were determined by using static tensile tests. The tests results obtained for the strokes impact of the gravel type irregular shape objects into the metal panels were presented in the article [10]. The experiments were used to prepare the process FEM models. As a result of conducted tests the analogical results for the simulation and the experiment were obtained. 
Numerical analysis results for the structure optimization of the frame carrying ropes suspension bracket of the electric lift using static loading and fatigue simulation were presented in this research study. Basically, there are two reasons for design modifications of the load-carrying structures. Economy and manufacturing costs reduction constitute the first one. Safety regulations which become more and more restricted are the second reason. They have a direct impact on the replacement costs of old lifting devices which do not fulfill the mandatory standard requirements [6]. Devices are being adjusted to the new regulations not only because of safety but also for the passengers' comfort. The comfort increase is understood herein as the cabin height increase.

In the publication [10] authors presented a quadrilateral element with smoothed curvatures for Mindlin-Reissner plates with FEM method use. The curvature at each point was obtained by a non-local approximation via a smoothing function. The bending stiffness matrix was calculated by a boundary integral along the boundaries of the smoothing elements (smoothing cells). Numerical results showed that the proposed element was robust, computational inexpensive and simultaneously very accurate and free of locking, even for very thin plates. The most promising feature of our elements is their insensitivity to mesh distortion. In addition to the above-mentioned areas of interest, the FEM method was used in the areas related to magnetism described in publication [9], vibration calculations of various thin-walled constructions [11], modeling of liquids, air and thermal loads as well as beams and trusses simulations [13].

It is impossible to install the higher cabin in the existing carrying frame without design modifications. It is due to the fact that the old carrying frames installed in the sky-scraper type buildings were manufactured based on the production standard developed in the 1970s.

Therefore, there are two situations where the higher cabin can be installed in the frame and operated safely:

- The replacement of vertical profiles of the frame for the longer ones, which is additionally connected with the analysis of safety zones availability in the lift pithead that is impossible in many cases;

- A design modification of the frame suspension. Placing the ends of the carrying ropes between the horizontal profiles of the frame.

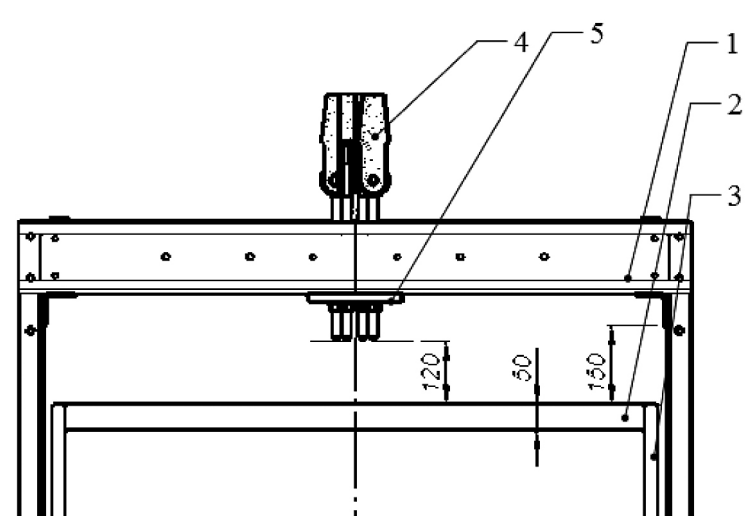

Fig. 1. The cross section of the carrying frame, the cabin and a new solution of the bracket of the carrying ropes suspension: 1 - the carrying frame, 2 - the cabin roof, 3 - the cabin walls, 4 - the carrying ropes endings (thimbles), 5 - the carrying ropes bracket (the existing solution)

The existing solution of the carrying frame manufactured in the 1970s and still available on the market is presented in Figure 1. The plate of the carrying ropes suspension (5) was located under the horizontal profiles of the frame (1). In consequence, the carrying ropes ends (4) protruded under the horizontal profiles of the frame (1) and made the installation of the higher cabin impossible in the existing frame. Maintaining 120 $\mathrm{mm}$ dimension between the ends of the frame carrying ropes endings and the cabin roof (2) was necessary because of the way subassemblies are installed. Moreover, the roof thickness which was smaller than $50 \mathrm{~mm}$ can lead to the loss of the roof stiffness. It is unacceptable as technical staff needs to perform maintenance work. In the solutions presented above, the ropes endings were fixed in the suspension plate holes. The plate was made of S235 grade and $16 \mathrm{~mm}$ thick sheet-metal ensuring its appropriate stiffness. The plate was subject to $9550 \mathrm{~N}$ loading. It is a sum of maximum loading capacity of the cabin, the frame mass and the cabin mass with the cabin doors.

The problem described above can be solved by using a different construction of the frame bracket. The bracket surface where the carrying ropes are mounted was hidden between the frame horizontal C-beams, as presented in Figure 2. The carrying ropes bracket (5) was placed between the frame carrying beams (1) so as the ropes endings (4) did not protrude under the beams. Thanks to this solution it was possible to increase the cabin height by $100 \mathrm{~mm}$. 


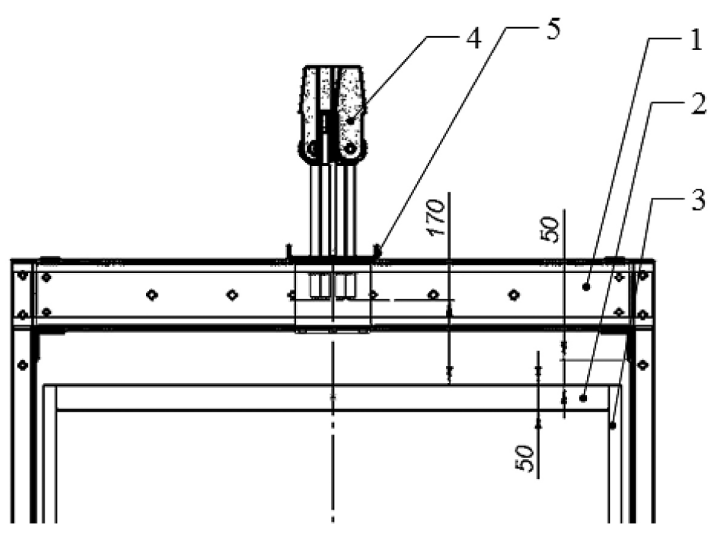

Fig. 2. The cross section of the carrying frame, the cabin and a new solution of the bracket of the carrying ropes suspension: 1 - the carrying frame, 2 - the cabin roof, 3 - the cabin walls, 4 - the carrying ropes endings (thimbles), 5 - the carrying ropes bracket (a new concept)

The bracket in the new solution, presented in Fig. 3, consisted of three sheet parts made of $4 \mathrm{~mm}$ thick sheet-metal. Apart from the main bracket (1b) the upper C-beam (3b) is a carrying element. An additional doubling plate (2b) was used under the main bracket in order to ensure proper strength.

The plate of the frame carrying ropes suspension (the old solution) was made with plasma cutting technology. The plate, together with the transversal profiles weighed $22.3 \mathrm{~kg}$. In the new solution the mass of the new bracket together with the frame transversal profiles was $23 \mathrm{~kg}$. Thus, it was $0.7 \mathrm{~kg}$ more. Such a slight difference in the mass would not have a negative impact on the carrying ropes loading. Therefore, it could be ignored in the further considerations.

a)

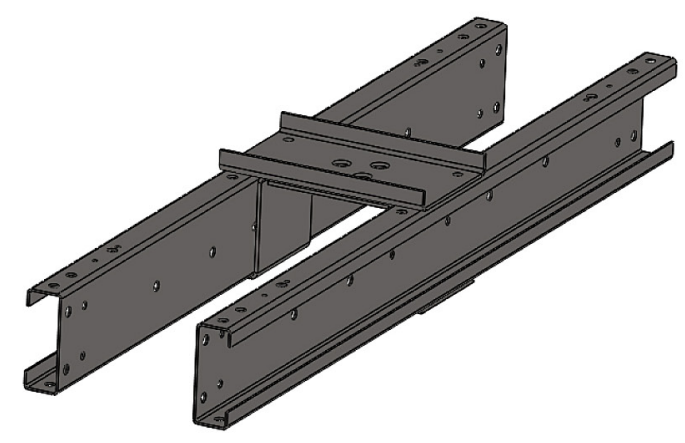

\section{THEORETICAL BACKGROUND}

Fatigue process developing in the structural materials subject to long-lasting cyclic loadings is constantly a significant problem for the present technique. The stresses that change in an oscillational way reduce the service life of the structure elements. This is so, as they can be damaged at the values of stresses significantly lesser than the static strength of the material that they are made of. Such a loss of material strength is generally understood as fatigue strength.

Fatigue is a common reason of premature destruction of the structure. Therefore, in practice this term means a finite number of the loading cycles which can be carried by a given material. There are many factors that have a direct impact on this limit of cycles. Among others, these are the following factors:

- the nature of loadings,

- the sequence of loadings,

- the duration of loadings.

Limited and permanent fatigue strength determined by a standard Wöhler's procedure is one of the main material parameters of engineering designing. However, it gives no reliable grounds to evaluate the evolution of damage process development under the impact of cyclic loadings [6].

The complete Wöhler's diagram is presented in Fig. 4. It is assumed that the value of destructive stress at $1 / 4$ of the cycle is comparable to a suitable strength limit under static loading. The following characteristic areas of fatigue strength are indicated in this diagram:

- $1^{\text {st }}$ area (quasi-static strength) - from $1 / 4$ to about $10^{3}-10^{4}$ cycles, where the material

b)

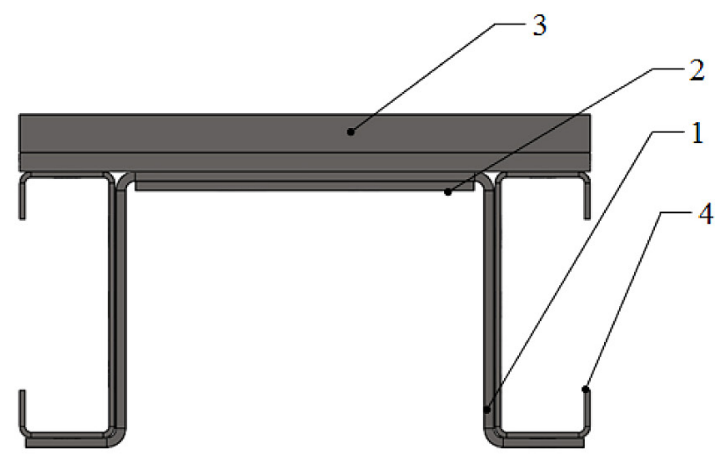

Fig. 3. The location of a new concept of the carrying ropes bracket in the existing frame of the lift: a) a general project, b) a side view: 1 - the carrying ropes bracket, 2 - the doubling plate, the bracket upper C-beam, 4 - the frame traverses 


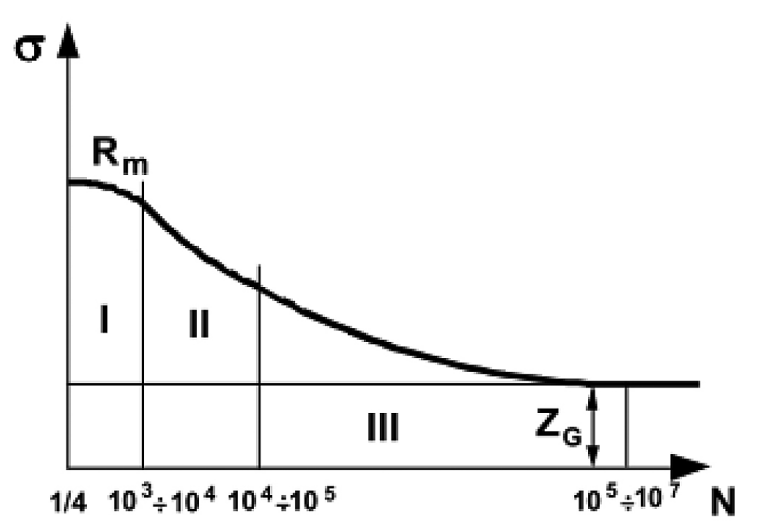

Fig. 4. Complete Wöhler's diagram in the coordinate system - nominal stress - the number of cycles to obtain damage [6]

fatigue cracking has the character of plastic cracking;

- $2^{\text {nd }}$ area (low cycle strength or low cycle fatigue) about $10^{4}$ to $10^{5}$ cycles, where the fatigue takes place in high stresses and in relatively high plastic deformations;

- $3^{\text {rd }}$ area (high cycle strength) - from $10^{5}$ to $10^{7}$ cycles, where the material cracking takes place at elastic strain comparable to the value of plastic strain.

There are several practical things that should be taken into account while making use of Wöhler's fatigue diagrams [6]:

- in the $2^{\text {nd }}$ and the $3^{\text {rd }}$ area the material destruction is caused by the fatigue damage cumulation;

- there are no clearly indicated boundaries between the areas;

- in the engineering calculations the $1^{\text {st }}$ area joins with the $2^{\text {nd }}$ one and they are treated as low cycle strength area;

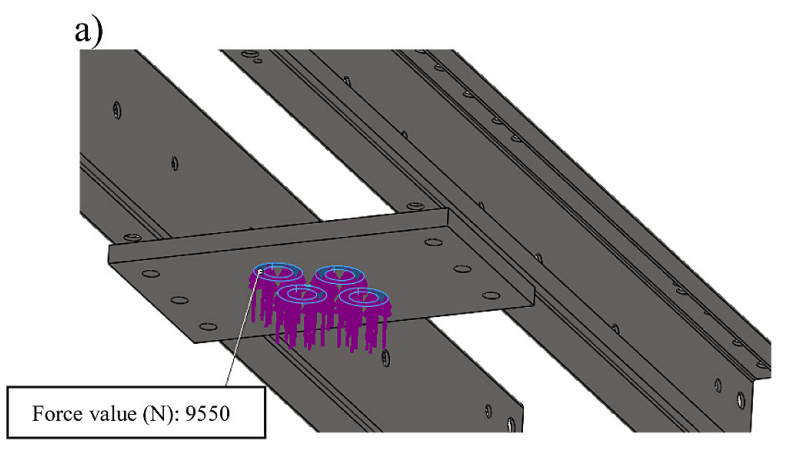

- in practice, in logarithmic system the whole diagram approximates with two straight lines: one line illustrates a diagram inclined line covering the scope of stresses greater than $\left(\mathrm{Z}_{\mathrm{G}}\right)$ fatigue limit and the second line - representing the fatigue limit.

\section{THE PURPOSE AND THE SCOPE OF NUMERICAL ANALYSIS}

The main purpose of the numerical analysis was to perform calculations of strength. On the basis of these calculations, the maximum displacements of the ropes bracket were determined. Moreover, the fatigue calculations in relation to the solution mounted under the frame horizontal beams were used for that purpose. The carrying frame, together with the cabin doors and the loading capacity, load the bracket with $9550 \mathrm{~N}$. Because of the nature of an electric lift operation, the structural elements of the carrying frame are subject to the loadings dependent on the carrying capacity. Carrying capacity corresponds to the number of passengers inside the cabin. Additionally, frequent stops and starts of the cabin lead to deformation of such elements as the ropes bracket and the frame horizontal beams. Such deformation is caused by the loading which is present in the alternating cycles of loading. For the lift with 11 stops, the number of stops and starts can reach 5000 cycles in a week assuming that the lift works constantly between respective floors for up to 9 hours each day. The remaining twenty-four-hour period stands for a night stoppage and a reduced number of drives during the remaining hours. The loading scheme which reduces the maximum value of stress resulting from the maximum loading was taken for the

b)

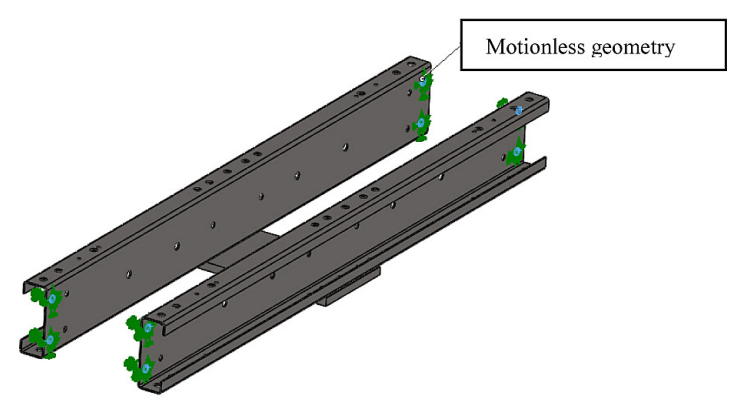

Fig. 5. Boundary conditions of the frame upper profiles assembly: a) the application of loading in the place of the carrying ropes, b) immovable mounting of the frame upper profiles 
a)

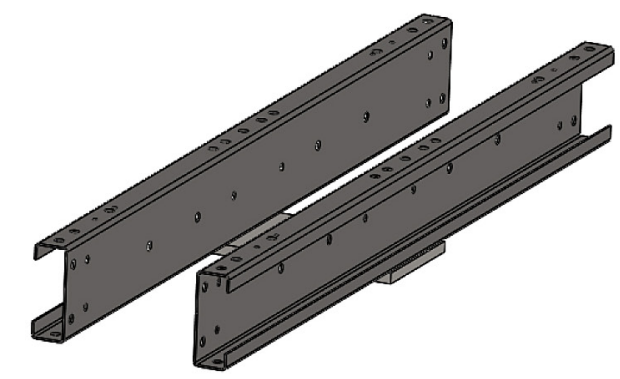

b)

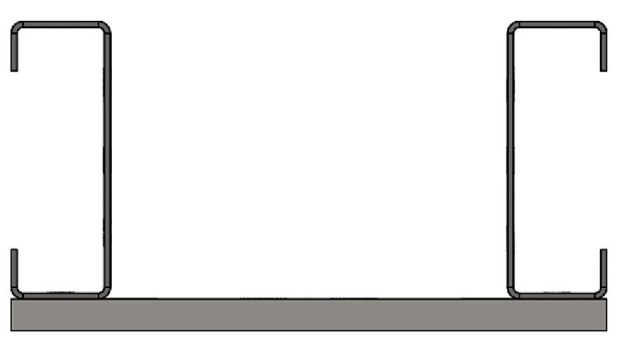

Fig. 6. The suspension plate of the carrying ropes in the existing solutions of the passenger lifts carrying frames: a) - a general view of the frame upper profiles with the suspension plate, b) - a side view

fatigue calculations due to the changeable loading of the frame. The value of proportionality coefficient for the maximum loading was 0.5 .

In the examined cases the loading was applied to the plate or to the carrying ropes bracket. It is presented in Figure 5.

It was assumed that the loading of the frame bracket is applied to 4 surfaces. The surfaces constitute the stop face of the rope endings of the lift carrying ropes with a total value of the loading $9550 \mathrm{~N}$. The attachment of the frame upper profiles was fixed rigidly; that is why the resolution in the attachment holes can be interpreted with (1), (2), and (3) identities:

$$
\begin{aligned}
& U_{X}=0 \\
& U_{y}=0 \\
& U_{z}=0
\end{aligned}
$$

The line-resilient characteristic of the material was adopted in the numerical calculations for the existing and the new version of the bracket. This is because no permanent deformations of carrying frame components take place when it is operated. All components of the frame were made of steel with the following mechanical properties:

- Young model $E=210 \mathrm{GPa}$,

- Poisson ratio $v=0.3$,

- Material density $\rho=7860 \mathrm{~kg} / \mathrm{m}^{3}$,

- yield point $R_{e}=230 \mathrm{MPa}$

It was assumed that huge displacements can appear in the optimized model due to the loading applied. Thus, the presented issue can be nonlinear from geometrical point of view. NewtonRaphson incremental-iterative method [1,3] was used in the calculations.

The carrying ropes suspension plate mounted in the solutions available on the market is presented in Figure 6.
The geometrical models of the analysed object in the form before and after optimization were both prepared in an assembly version by using CAD - Solid Works 2016 software based on drawing documentation. The geometrical model of the carrying frame was a basis to develop a discrete model for the analyzed object. It allowed performing numerical calculations by using finite element method. A discrete model of the upper profiles in the new solution in the places where the loading was applied is presented in Figure 7.

A geometrical model discretization was performed using volumetric finite elements with a global size of the mesh element 5 with 0.25 tolerance.

\section{NUMERICAL CALCULATIONS RESULTS}

Two-stage numerical analysis was conducted for each solution. In the first stage, the maximum displacements were calculated both for the suspension plate of the carrying ropes and for the op-

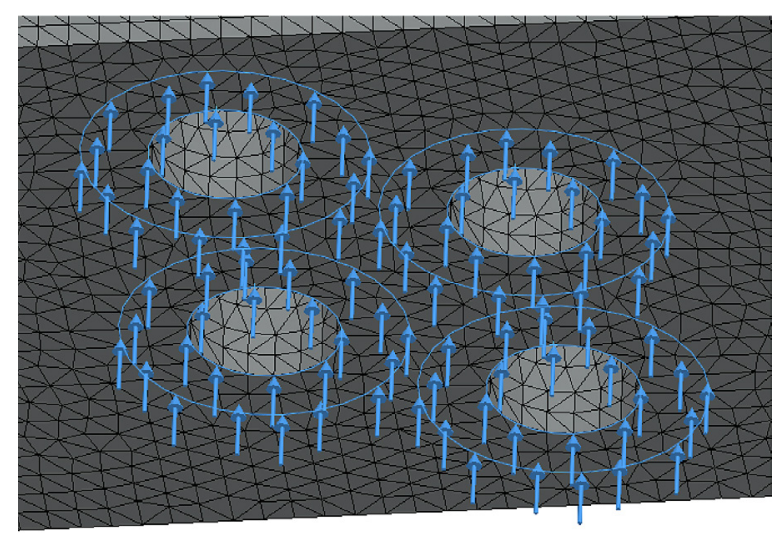

Fig. 7. The view of loading applied to the carrying ropes bracket with FEM mesh applied 

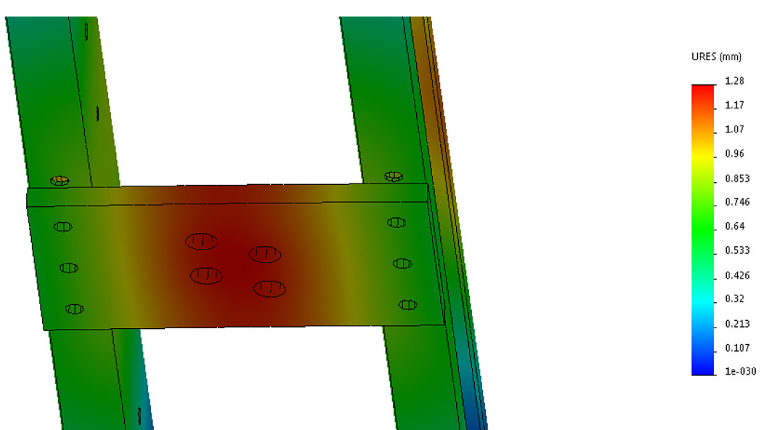

Fig. 8. Displacement of the plate for the carrying ropes suspension

timized bracket of the ropes. In the second stage, durability of both solutions was determined. Additionally, percentage probabilities of the bracket damage caused by the loading were specified. The displacements values for the suspension plate based on the spatial model are presented in Figure 8. The values of displacements of the bracket installed for the ropes suspension are presented in Figure 9.

Numerical analysis of both solutions confirmed that the elements to which the carrying ropes were mounted are to be deformed the most. In both cases these are the strains of elastic nature. The value of the suspension plate deformation was $1.28 \mathrm{~mm}$ and for the bracket $-1.56 \mathrm{~mm}$. On the basis of the above mentioned analysis it can be stated that it is possible to optimize the structure of a plate intended for the bracket. The bracket is manufactured with bending technology ensuring time savings from the production point of view. The time necessary to prepare the carrying ropes suspension plate with plasma cutting
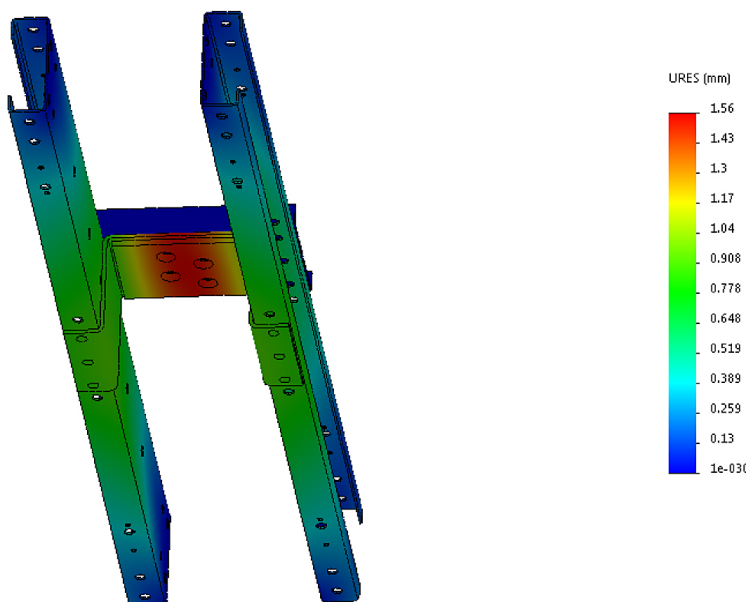

Fig. 9. Displacement of the bracket for the carrying ropes suspension

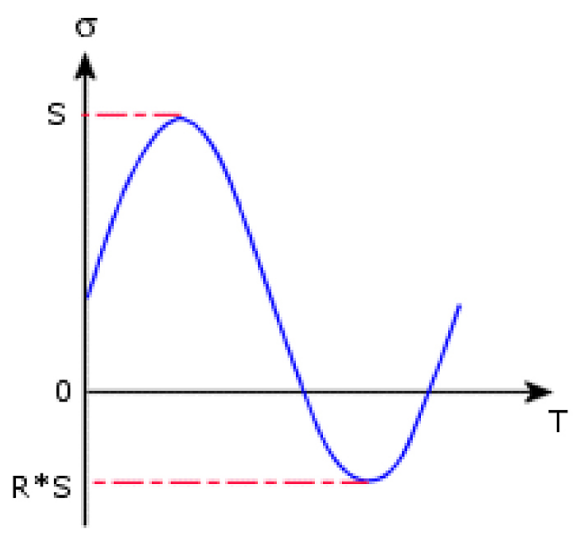

Fig. 10. A theoretical model representing the stress reduction in the structure with $\mathrm{R}$ [16] proportionality indicator applied

technology approximately amounts to $10 \mathrm{~min}$ utes. In comparison, the time necessary to prepare the elements of the bracket with laser cutting technology is 2 minutes. In contrast, the bending operation of respective detail parts is 1 minute. Considering the above-mentioned aspects from the economical point of view, the indirect costs of technologies themselves are also significant. However, in this study attention was paid to the time of respective detail parts manufacture.

Subsequently, the performed spatial models were used to estimate the percentage value of damage probability for respective solutions caused by the loading applied. For that purpose, a fatigue model was taken where the maximum stresses generated in the structure due to the loading were reduced proportionally by $\mathrm{R}=0.5$ proportionality indicator. The above described model a presented in Figure 10.

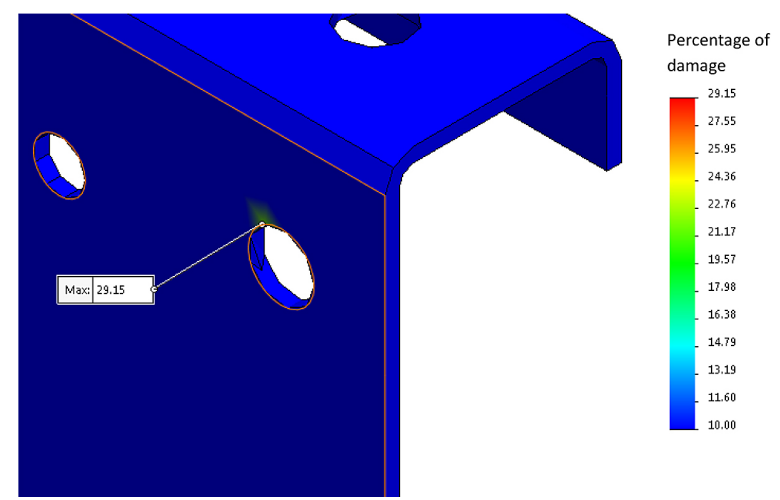

Fig. 11. A percentage indicator of the model damage together with the carrying ropes suspension plate: a hole detail with a maximum value of a damage percentage indicator 

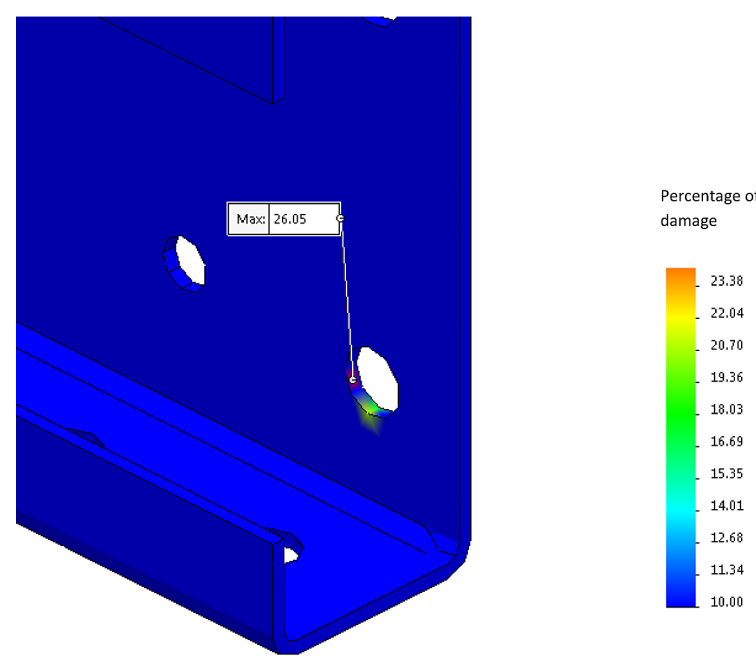

Fig. 12. A percentage indicator of the model damage together with the carrying ropes suspension plate: a hole detail with a maximum value of a damage percentage indicator

It was assumed for the prepared models that the probability indicator would reduce the stresses to a maximum possible extent. In both cases the value was $\mathrm{R}=0.5$. It means that when the lift starts and brakes on the stops the cabin frame and at the same time the bracket are subject to damped loadings. The percentage values of damage probability for both solutions are presented in Figure 11 and 12.

In both presented cases, when the manner of the structure effort is known, it is possible to estimate a percentage value of its damage. In the first example, the probability of damage in the areas close to the horizontal profiles holes located in the frame was $29.15 \%$. This kind of damage is
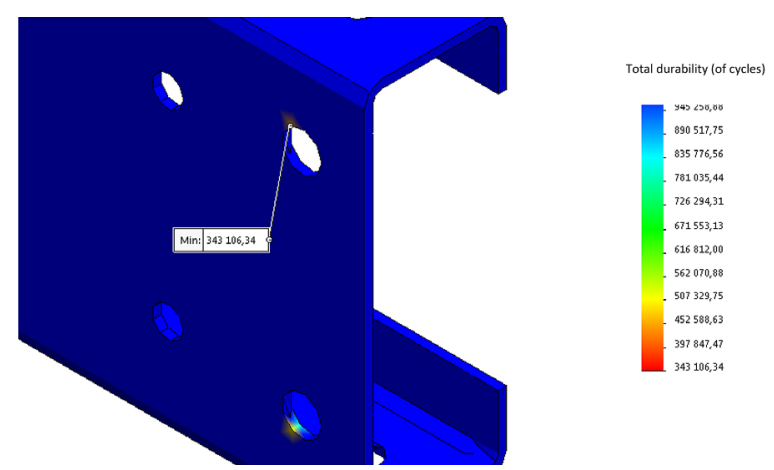

Fig. 13. Durability indicator of the structure with the carrying ropes suspension plate: a) - a general view, b) - the place with the lowest value of durability indicator

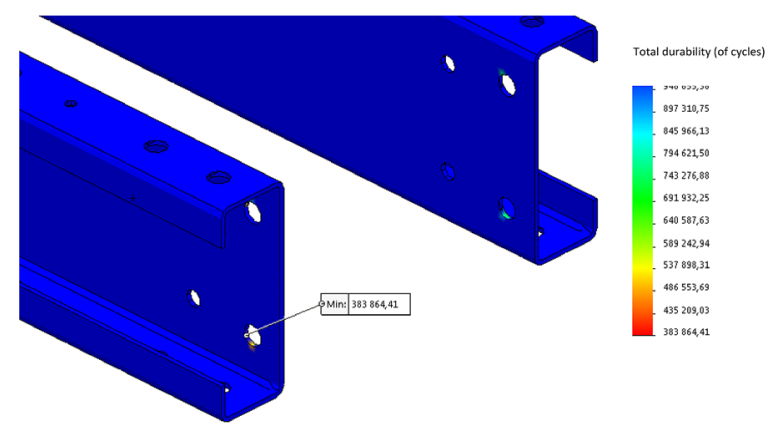

Fig. 14. Durability indicator of the structure with the carrying ropes suspension plate: a) - a general view,

b) - the place with the lowest value of durability indicator

caused by the fatigue stresses. The indicator for the bracket of the ropes suspension was calculated in a similar way. For the optimized solution, the first damage would also appear in the attachment holes with $26.05 \%$ probability. On the basis of the obtained results of calculations it can be stated that the durability of both solutions is practically unlimited.

Afterwards, the durability of respective solutions was estimated based on the conducted calculation analysis. The results of the analysis are presented in Figure 13 and 14.

The coefficients of the structure durability presented in Figure 13 and 14 mean that the first damage of the profiles structure in the lift frame would appear after 396523 cycles for the ropes suspension plate and after 383864 cycles for the ropes suspension bracket.

A conclusion can be drawn that the first damage in a form of cracks would appear in the holes which mount the horizontal profiles of the carrying frame. Relating these values to Wöhler's diagram, the number of fatigue cycles of both structures, calculated on the basis of a numerical analysis, is within the 3rd area of a diagram. On the basis of the numerical analyses it is possible to predict such indicators as durability or the exact place of the carrying systems damage. Such knowledge can be used both in research and development studies as well as for virtual prototyping.

\section{CONCLUSIONS}

Modeling of the carrying systems by using Finite Element Method, durability calculations and a percentage indicator of the applicable structures 
damage were presented in this research work. A simulation of the carrying ropes suspension in a friction lift proved that it is possible to modify the structure. A modification allows receiving similar values of indicators. Thus, the carrying ropes failure-free operation would have similar period of service life. The possibility to conduct the analysis at the stage of virtual prototyping is important when the new structural solutions are searched for and when there are too many unknown structural parameters at the stage of designing some complicated elements of machines and mechanisms. The knowledge on stresses layout in the component elements of the carrying system constitutes a significant issue. Solving this issue would allow evaluating the adopted concept. The numerical analysis of the system allowed optimizing the model parameters to design the most favorable solution focusing on the possibilities of transferring certain operational loadings. The analysis allowed assessing the necessary modifications of structural details in order to obtain an optimum solution.

Numerical calculations conducted with Finite Element Method for the friction lift carrying frame proved that it is possible to introduce design modifications for the bracket and reduce its time of manufacture from 10 minutes to $3 \mathrm{~min}$ utes. The modification presented is fundamental both from the operational and economic point of view. The performed analysis allowed evaluating the proposed design solution. It was a basis to launch necessary manufacturing modifications.

\section{Acknowledgement}

This research work has been financed within cooperation with LIFT POL company. The enterprise aimed at developing the company in modernization market of passenger lifts in Poland.

\section{REFERENCES}

1. Adamus J., Winowiecka J., Dyner M., Lacki P. Numerical simulation of forming titanium thin-wall panels with stiffeners. Advances in Science and Technology Research Journal Volume 2018, 12(1), 54-62, DOI: 10.12913/22998624/80826.

2. Czmochowski J., Smolnicki T., Rusiński E.: Advanced Finite Element Method in the supporting structures. Of. Wydawnicza Politechniki Wrocławskiej, Wrocław 2000.
3. Dębski H., Koszałka G., Ferdynus M.: Application of fem in the analysis of the structure of a trailer supporting frame with variable operation parameters. Eksploatacja i Niezawodność - Maintenance and reliability 2012; 14 (2): 107-114.

4. Kacprzyk Z., Rakowski G.: Finite Element Method in the mechanics of structures. Of. Wydawnicza Politechniki Warszawskiej, Warszawa 2005.

5. Kaiwu C., Wei Ch., Jifu L.: Finite element analysis on the bending condition of truck frame before and after opening. AIP Conference Proceedings 1967, 2018: 1-7; https://doi.org/10.1063/1.5039032.

6. Kowalewski Z. Fatigue of materials - the basics, the research studies directions, a damage condition assessment. XVIIth Seminary Materials Nondestructive Testing. Zakopane 2011.

7. Lonkwic P., Różyło P., Dębski H.: Numerical and experimental analysis of the progressive gear body with the use of finite-element method. Eksploatacja i Niezawodność - Maintenance and Reliability 2015; 17 (4): 544-550, http://dx.doi.org/10.17531/ ein.2015.4.9.

8. Markowski T., Mucha J., Witkowski W.: FEM analysis of clinching joint machine's c-frame rigidity. Eksploatacja i Niezawodność - Maintenance and reliability 2013; 15 (1): 51-57.

9. Meeker D.: Finite Element Method Magnetics. USA 2015.

10. Nguyen-Xuan N., Rabczuk T., Stéphane B., Debongnie F. A smoothed finite element method for plate analysis. Computer Methods in Applied Mechanics and Engineering 2008; 197 (13-16), https://doi.org/10.1016/j.cma.2007.10.008.

11. Ping Zhua Z., Leiabc X., Liewab K., M.: Static and free vibration analyses of carbon nanotubereinforced composite plates using finite element method with first order shear deformation plate theory. Composite Structures 2012; 94 (4), https:// doi.org/10.1016/j.compstruct.2011.11.010.

12. PN EN 81-20 Standard Safety Rules For The Construction And Installation Of Lifts - Lifts For The Transport Of Persons And Goods - Part 20: Passenger And Goods Passenger Lifts, Warszawa 2017.

13. Rao S. Singiresu: The Finite Element Method in Engineering. Butterworth-Heiner of Elsevier, USA 2018.

14. Szydło K., Longwic R.: Diagnostics of the passenger lift gear. Advances in Science and Technology Research Journal 2018; 12(1): 26-35.

15. Vosáhlo J., Syrovátková M., Petrů M. Numerical model ling of behaviour of surface finishing of composite materials. 2018, Volume 12(1), 48-53, DOI: $10.12913 / 22998624 / 81449$.

16. www.solidworks.com 